\title{
How to Improve Power System Reliability in Ghana
}

\author{
Bernard Adjei-Frimpong ${ }^{1}$, Kingsley Akom ${ }^{2}$, Johannex Fefeh Rushman ${ }^{3}$ \\ ${ }^{1}$ Kumasi Polytechnic, Department of Electrical Engineering, P.O. Box 854, Kumasi, Ghana \\ ${ }^{2}$ Department of Electrical Engineering, Kumasi Polytechnic, P.O. Box 854, Kumasi, Ghana \\ ${ }^{3}$ Kumasi Polytechnic, Department of Electrical Engineering, P.O. Box 854, Kumasi, Ghana
}

\begin{abstract}
The prospects for nation building, economic development, industrialization, have made countries across the world to development reliable power systems for implementation. Power generation, transmission and distribution are capital intensive and require huge resources of both funds and capacity. In emerging economies like Ghana where funds availability is progressively dwindling, creative and innovative solutions are priorities to address the power supply problem. The purpose of the paper is to highlight on the effect of power reliability on generation, transmission and distribution. In working towards proposing effective power system reliability, current system technologies were reviewed. We look at the impact on development and economic growth. Improve methods have been analyzed as solution to determine how power reliability can be managed to maintain effective systems operation. The paper presents basics on how power system works, reliability effects, and reliability assessment on power generation, transmission and distribution. its impact on the economy and development.
\end{abstract}

Keywords: reliability, distribution, transmission, generation

\section{Introduction}

The main functions of an electric power system are to satisfy the system load requirement with a reasonable assurance of continuity and quality. The system's ability to provide and maintain adequate supply of electrical energy is usually termed as reliability. The concept of power-system reliability is extremely broad and covers all aspects of the ability of the system to satisfy the customer requirements. The concept of power system reliability is subdivided into system adequacy and system security. System adequacy relates to the existence of sufficient facilities within the system to satisfy the consumer load demand. The facilities are able to generate sufficient energy and the transmission and distribution tools required to transport the energy to the actual consumer load points. While security relates to the ability of the system to respond to disturbances arising within that system. Security is associated with systems response to any perturbations it is subject to [8]. The techniques presently available for powersystem reliability evaluations are in the domain of adequacy assessment.

System adequacy is tied to forecasting (load and capacity) and power system reliability evaluations which may be conducted separately in the functional areas of generation, transmission and distribution. Assessments can also made in the combined generation and transmission systems, called composite or bulk system evaluation. In reliability evaluation, the total system generation capacity is examined to determine its adequacy to meet the total system load requirement.

The power situation in Ghana's today represents a critical obstacle to the nation's economic growth. Currently, the country has nominal generation capacity of about $2,400 \mathrm{MW}$ and dependable generation capacity of around 1,750MW. This has resulted in generation deficit in excess of 600MW as a result of lower than expected output from its hydroelectric installed base and the reduced output of its thermal power plants due to maintenance and fuel cost. But increasingly, lower reservoirs at the Akosombo dam have increased dependency on light crude oil (LCO) to fuel Ghana's thermal power generators. While oil is now dependable and the recent drop in oil prices has had a positive impact on the cost of electricity generation, it remains one of the most expensive fuels to generate electricity over the long run - both from a financial and emissions perspective. In this regard, Ghana is seeking to develop cost-effective natural gas to generate electricity and not depend on imported light crude oil which quite expensive. In early 2015, however, the short term urgency of the power crisis became apparent with increased load shedding, which has affected all households and sectors of the economy.

\section{How Power System Works}

An electrical power system comprises of three main sections, that is generation, transmission and distribution systems. The function of the entire system is to transfer energy from the available resources to the end consumers. Electric power is typically generated at very low voltages such as $13 \mathrm{kV}$ to 24 $\mathrm{kV}$ at power stations. In Ghana, the power station at Akosombo generates power at $14.4 \mathrm{kV}[1]$. This power is then transmitted over long distances to bulk load centers located at Accra, Kumasi and Tamale. The transmission is done at high voltages to minimize transmission losses. The primary bulk power transmission voltage in Ghana is $161 \mathrm{kV}$. At the bulk power distribution centre, the power is stepped down through step-down transformers for wholesale power buyers such as ECG and NED for further distribution through their respective distribution networks to their customers. 


\section{International Journal of Science and Research (IJSR) \\ ISSN (Online): 2319-7064}

Index Copernicus Value (2013): 6.14 | Impact Factor (2015): 6.391

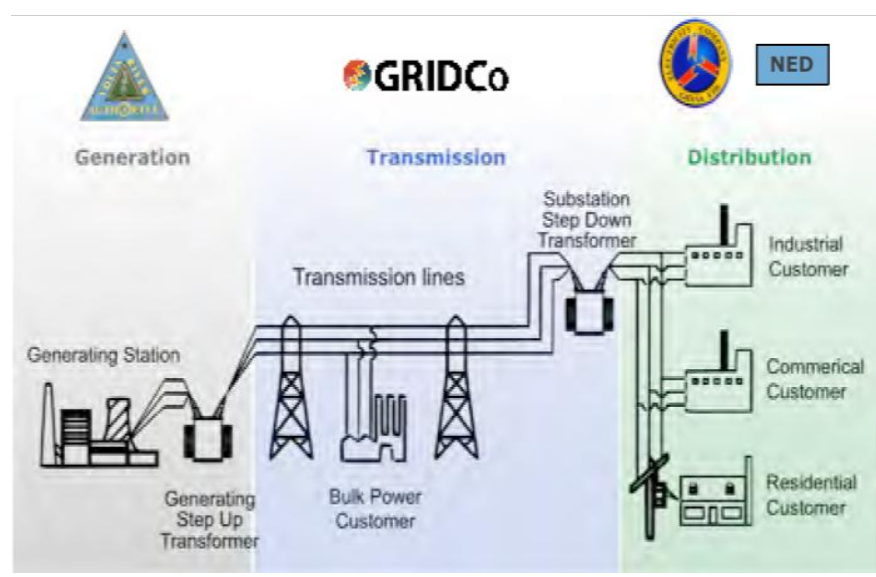

Figure 1: Basic power network by: Ghana Grid Company Limited

Each of the three section of the whole power system comprises of many interconnected elements. When each of these elements function as expected, we get a functioning sub-system, and combined with other functioning subsystems, a reliable power system. Any elemental failure can compromise the reliability of the entire system; therefore planners and operators allow necessary redundancies for critical elements to ensure reliable supply. A well-designed and reliable power system must have adequate redundancies so that an unplanned elemental failure such as the outage of a single transmission line, transformer or generator will not cause a partial or total power outage.

Although, the redundancies needed in the power system, such as power lines and power transformers are generally of a physical nature, there are often structural issues that inherently prevent the timely deployment of these physical resources. We cannot address power system reliability without examining the structural issues that potentially affect the deployment of these physical resources. Therefore, it is important for us to broadly examine all the direct and indirect factors that affect reliability.

\section{Factors that Affect Reliability}

A well designed and reliable power system has sufficient redundancies to accommodate unplanned elemental outages without causing a failure of the system. Redundancies are of a physical nature and structural issues may impair the deployment of these physical resources. We will examine the structure of the power industry in Ghana and identify potential structural impediments that negatively affect reliability [8].

Most power companies around the world are structured as public monopolies with extensive integration of generation, transmission, and distribution services and centralized planning of supply resources to meet demand growth [9]. These integral structures were believed to maximize coordination and efficiency in the design, development, and financing of wholesale power supply resources. In order to prevent abuse of monopoly of power, utilities were regulated by government and allowed a fixed rate of returns above their cost. Over time it became self evident that the state-owned, vertically integrated monopoly structure was plagued by poor performance and limited capital for operations and investment.

Lack of competition due to government monopoly in managing the system, accounts for the poor performance and managerial deficiencies. There are three high amount of nontechnical losses in the system. These losses are difficult to eradicate because it is observed that it is not politically correct to clamp down on these practices.

Again, managerial decisions at state-owned public utilities were heavily influenced by government objectives which are not consistent with the utility's business objectives. It has always been a challenge for government to adjust tariffs to ensure full cost recovery given the impact on the consumers (i.e. voters). As a result, tariffs lagged the full cost of power production and delivery, and in many cases could not cover even variable operating costs. These factors, borne out of the fully regulated state-owned monopoly structure, severely compromised power supply reliability, and in many countries like Ghana, it hinders economic development.

\section{Transmission Reliability}

Transmission reliability involves an efficient network of substations and a transmission line linked from generation sources to load centers and allows the wholesale power system to transport power from generation resources to bulk consumers. Table 1 provides an overview of Ghana's transmission network. This network comprises over $4,000 \mathrm{~km}$ of $161 \mathrm{kV}$ high voltage transmission lines, $72 \mathrm{~km}$ of $330 \mathrm{kV}$ transmission lines, and $132 \mathrm{~km}$ of $69 \mathrm{kV}$ transmission lines. Current implementation of a series of $330 \mathrm{kV}$ transmission projects will result in $330 \mathrm{kV}$ replacing $161 \mathrm{kV}$ as the primary backbone transmission voltage. While, transmission lines are linked to 42 primary substations with a combined installed transformer capacity of 2,850 MVA. At the substations, voltage is reduced to $34.5 \mathrm{kV}, 11.5 \mathrm{kV}, 6.6 \mathrm{kV}$ for supply to bulk supply customers and for onward distribution to end users [1].

Ghana's power transmission network is interconnected with Côte d'Ivoire on the western side of the country through a single circuit $225 \mathrm{kV}$ and to Togo and Benin on the eastern side through a double circuit $161 \mathrm{kV}$ interconnection. On the northern frontier Ghana is preparing to supply electric power to Burkina Faso using high voltage transmission system under development as part of the WAPP agreement [9].

Table 1: Fact sheet on Ghana's transmission network

\begin{tabular}{|l|r|}
\hline Total Transmission Line Length & $4,244 \mathrm{~km}$ \\
\hline $161 \mathrm{kV}$ Line Length & $4,038 \mathrm{~km}$ \\
\hline $225 \mathrm{kV}$ Line Length & $73.4 \mathrm{~km}$ \\
\hline $69 \mathrm{kV}$ Line Length \\
\hline \multicolumn{2}{|c|}{} \\
\hline Number of Transformers & $132.8 \mathrm{~km}$ \\
\hline Transformer Capacity & 86 \\
\hline Number of Transformer/Switching Substations & $2,850 \mathrm{MVA}$ \\
\hline Transformer Substation Voltages & 42 \\
\hline
\end{tabular}

Courtesy: The National Grid", Ghana Grid Company Limited, 2010 


\section{International Journal of Science and Research (IJSR) \\ ISSN (Online): 2319-7064}

Index Copernicus Value (2013): 6.14 | Impact Factor (2015): 6.391

\subsection{The concept of establishing transmission reliability}

In single line transmission, the thermal rating is one of the limits to power flow. Any network system which of consists of single or many lines, have other factors imposing limits on the power transfer across them. The factors include contingencies made up of unplanned transmission outages, system stability, and voltage requirements. These limits imposed can be more restrictive than the thermal limits of the transmission lines. In case of any unplanned transmission facility outage, the pre-outage power flow on that facility is automatically redistributed on other connected facilities still in operation. Any transmission facility not able to operate safely and reliably accommodate incremental flow, will also trip out of circuit, establishing the risk of a cascading outage and a blackout. Under normal operations transmission facilities have sufficient margin to accommodate incremental power flows from an unexpected loss of another facility. There is a likelihood contingency constrains system put in place to regulate the power carrying capability of connected transmission facilities within preset limits.

Another limit on the transmission network is the voltages at substations. A well-designed and operated power system must have constant voltage magnitude. Voltages at substations should be maintained close to their rated value for reliable system operation. When voltages decline below nominal values, the reliability of power to areas of the network is low. Significant deviation voltages from their nominal levels, will result in instability, which could lead to a blackout. For reliable operations, the voltages at substations of the power system network must be regulated within a $5 \%$ tolerance band of their nominal rating. This means, voltage at a $161 \mathrm{kV}$ substation must be regulated within a tolerance of $153 \mathrm{kV}$ and $169 \mathrm{kV}$. The transfer of power across the transmission network, losses cause voltages to drop. These increase with increasing power transfer and if not regulate within the $5 \%$ tolerance band, may cause system collapse. Thus, to prevent voltages from dropping below their tolerance limits, operators set conservative voltage stability limits for power transfers across a single transmission facility or group of facilities.

Another limitation imposed on the amount of power transferred is the power angle stability limit. The power angle must be kept very small to preserve the capability of the power system to naturally dampen any oscillations that could cause instability. While the theoretical limit of the power angle could be as high as ninety degrees to maximize the amount of power transferred, it is not practically achievable due to the risk of uncontrollable oscillations that can lead system collapse. Operators must always keep transfer capability below a maximum threshold to maintain power system stability. This preset transfer level is the power angle stability limit.

The transmission capacity power systems, available for reliable power transfers are measured by the Total Transfer Capability (TTC). TTC already accounts for thermal, voltage power angle stability considerations. In addition transmission capacity margins can be reserved from the TTC to augment local demand in case of low generation. Other transmission capacity margins must also be reserved to allow the system to handle uncertainties such as load forecast errors and power flows in excess of the projected levels. The Capacity Benefit Margin (CBM) is the amount of transmission capacity reserved for local load to ensure that local demands are reliably. while the capacity reserved to handle uncertainties is called the Transmission Reliability Margin (TRM), the margins act as spare capacity for the system to continue to operate reliably during unexpected demand arise. This margin when subtracted from the TTC determines the capacity available for commercial energy transfers from one part of the network to another. Moreover, Transfer Capability (ATC) is a measure of transmission capability remaining for commercial energy transfers net of committed uses, i.e. it is the TTC after netting out CBM and TRM and any capacity already allocated for existing long-term power contracts. (ATC $=$ TTC - CBM - TRM- Committed Uses). A measure of transmission reliability is to determine the adequacy of ATC between various areas of the transmission system.

Transmission congestion occurs when demand is higher than power available for transmission. When there is no transmission congestion, operators have the flexibility to use the most economical generation resources to serve demand. This produces the least cost to consumers.

Eliminating all transmission congestion is not necessarily economic, especially if system operators have the option to re-dispatch generation to relieve congestion on the constrained transmission facility. Due to the high cost of transmission infrastructure, it can be very expensive to build a transmission system that has no transmission congestion and in Ghana's situation where all generation resources are located in the south, major transmission constraints to power deliverability to the northern sector like Kumasi, Techiman and Tamale could mean load shedding as operators would have no generation re-dispatch options. This is the reason why the proposed location of the Bui dam is advantageous; since the plant will provide GRIDCo with valuable generation re-dispatch options in the event of transmission congestion in the delivery of power from the south to areas such as Kumasi.

\section{Reliability in Distribution}

In a developing country like Ghana, power distribution reliability system is crucial to both utilities and customers. Distribution reliability has the potential to negatively affect public health and safety, economic growth and development, and societal well being. It can also cause low financial performance, industrial and commercial service. Many utilities may estimate the value of electric services to consumers to assess the benefits of investments to improve reliability [9]. Transmission reliability problems mostly come from power outages. These power outages in most cases come from weather related damage to overhead power lines. High winds can also cause trees to touch power lines, and sometimes cause poles to fall down. Other sources are animal contact, vehicle accidents, equipment failure, and human error. There are three main outages types of outages termed 


\section{International Journal of Science and Research (IJSR) \\ ISSN (Online): 2319-7064}

Index Copernicus Value (2013): 6.14 | Impact Factor (2015): 6.391

as major events, sustained interruption and momentary interruption.

- Major Events are due to activities that exceed the reasonable design or operational limits of the electric power system and affect a large percentage of the customers served by the utilities.

- Sustained Interruptions include outages not classified as momentary events and that last for more than five minutes.

- Momentary Interruptions involve the brief loss of power to one or more customers caused by opening and closing of interruption devices

Fewer interruptions for commercial and industrial customers often mean higher levels of output and productivity and lower levels of scrap and spoilage.

The benefits of fewer outages for residential customers range from greater convenience, to savings from less food spoilage, to avoidance of medical and safety problems.

\section{Improving Reliability}

Due to robust growth forecasts, the addition of generation capacity over the next 5-10 years remains key to maintaining a healthy reserve margin and ensuring the reliable operation of Ghana's electric system for the 2010 to 2018 period. The four key capacity additions between 2010 and 2014 has increase capacity to $1,270 \mathrm{MW}$. These four power plants are Sunon Asogli Power Plant (SAPP), Osagyefo Power Plant, Kpone Power Project (KPP), operating on natural gas/light crude oil and Bui Power Plant (BPP) which is hydro based. A steady increase in addition of other generations sources coupled with renewable energy will create a large reserve margin to ensure reliable supply and improve system security.

New techniques have also been developed to improve distribution system reliability, such as intelligent system monitoring, automatic switches and breakers, Microprocessor based Relays, power systems quality, setting up remote controlled substations and on a more complex level, reliability-centered maintenance is a recommended practice where maintenance requirements are determined based on equipment condition, criticality to the functioning of the system, and cost. This provides a repair and replacement schedule that optimizes system reliability by selecting high maintenance priority for components that are most likely to fail, and have a high impact on customers when they fail, and can be maintained for a reasonable cost. The implementation of this fault locating, isolation, and service restoration operations are also very important toward maintaining reliability. Some of the benefits are reduction of frequency of outages and outage duration.

The simplest way of ensuring transmission reliability is by tree-trimming, which must be very frequent, animal guards and lightning arrestors. In rural areas there should be bush clearing around the poles to avoid bushfire destruction. Regular inspection, maintenance and outage-prevention programs can provide valuable reliability-related data to support decision making.

\subsection{Impact of Economic Reliability}

Electricity is one of core elements for economic growth. It is responsible for wide range of products and services that improve quality of life, increase worker productivity, and encourage entrepreneurial activity. A reliable and accessible electricity system is critical in enabling Ghana to meet its long-run economic development goals.

For local consumption, it helps in lighting, on productivity through more efficient process heating and cooling, and on health through reduced indoor air pollution and the refrigeration of foods. In that process we become well educated, more productive, and have healthier workers who become key building blocks of economic productivity.

Commercial and industrial consumption of electricity in Ghana has been driven primarily by mining companies (responsible for extraction and transformation of resources). However, reliable and widespread access to electricity will be key to the development and sustenance of the secondary (manufacturing) and tertiary sectors (services and information). These sectors are key drivers of modern economies and hence critical to a robust, diversified economy with improve awages.

\section{Conclusion}

The reliability of the bulk power system depends on more the combined reliability of the Generation, transmission and the distribution. In this paper we assessed Ghana's generation reliability, transmission reliability and distribution reliability system.

Ghana can only achieve sustained economic growth and higher living standards through sustained development of electric power markets as part of its basic infrastructure. The ever-increasing demand can only be met by timely investments in new power generation, transmission and distribution facilities to improve reliability. A well laid market structure must also be developed to attract private investment.

The electricity consumers must also be educated on level of reliability they should expect and all parties can compare the costs of improving reliability through system improvements, and improving reliability through customer-side measures (e.g. installing UPS), and costs incurred by the customers if reliability is not improved. This will bridge the gap between generation, transmission, and distribution reliability assessment because it looks not only at the value of reliability but also at how best to improve the reliability at all stages of the power system.

\section{References}

[1] “Akosombo Brochure", Volta River Authority, 2010 http://www.vra.com/Publications/akobrochure.pdf

[2] Appleyard, J.C., Myers, D.A., Niemira, J.K., Innovations in use of microprocessor relays and controls for improved reliability on the distribution system, 
Transmission and Distribution Conference and Exposition, 2001 IEEE/PES Volume 1, 28 Oct.-2 Nov. 2001 Page(s):293 - 298 vol.1

[3] IEEE, "Probability Analysis of Power System Reliability," IEEE Tutorial, Course Text 71 M30-PWR, 1971.

[4] Electric Power Research Institute, Dynamics of Interconnected Power Systems, A Tutorial for System Dispatchers and Plant Operators, prepared by Power Technologies, Inc., Schenectady, N.Y., for the Electric Power Research Institute, Palo Alto, Calif., May 1989.

[5] Gerald Heydt, Electric Power Quality, Stars in a Circle Publications, December 1991

[6] L. Wehenkel. "Automahc learning techniques in power systems." Kluwer Academic, Boston, 1998

[7] P.S. Harish, L.A. Basha, G. Prashant, Automatic vacuum capacitor switch with modified digital filter design for enhanced speed and power optimization, Power Systems Conference and Exposition, 2004. IEEE PES, Page(s):568 - 573, vol.1, Oct. 2004

[8] Roy. Billinton, Ronald N. Allan, Power-system Reliability in Perspective, IEE J. Electron. Power, vol.30, pp.231-236, March 1984.

[9] Sarah Keener and Sudeshna G. Banerjee, Ghana: Poverty and Social Impact Analysis of Electricity Tariffs, ESMAP Technical Paper 088, December 2005

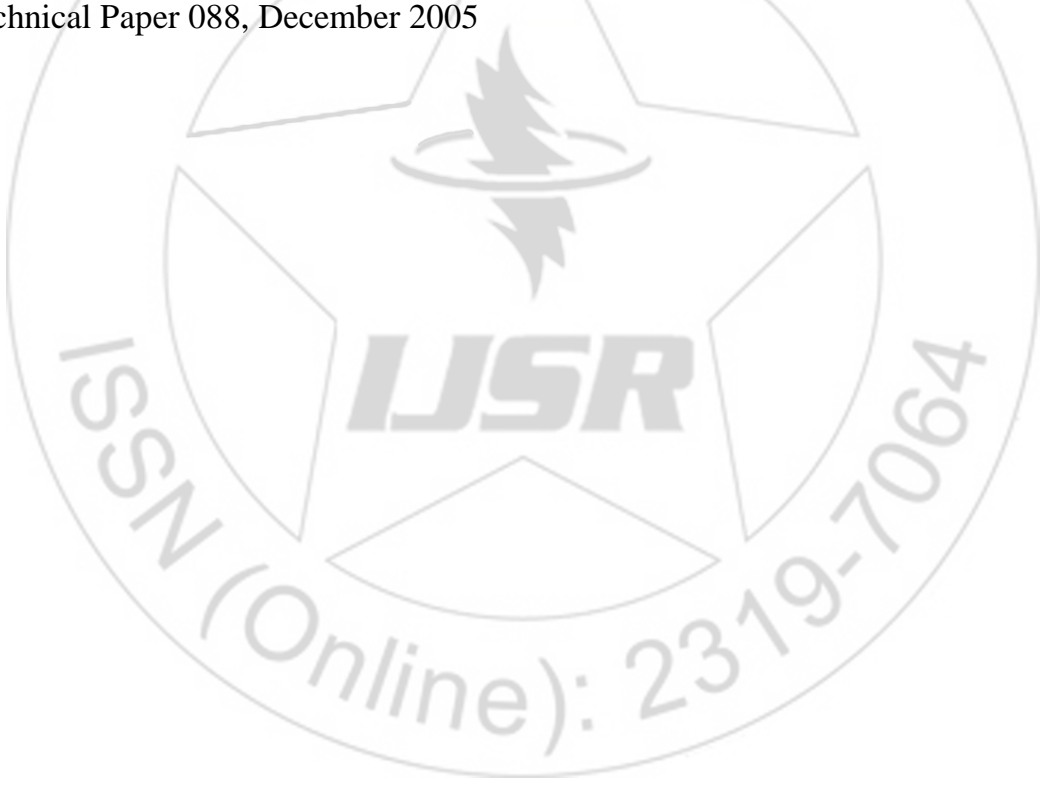

